\title{
Analysis of the vertical borehole stability in anisotropic rock formations
}

\author{
Yan Jin · Jianbo Yuan $\cdot$ Bin Hou $\cdot$ Mian Chen $\cdot$ \\ Yunhu Lu $\cdot$ Song $\mathbf{L i} \cdot$ Zhipeng Zou
}

Received: 26 May 2011/ Accepted: 13 August 2012/Published online: 5 September 2012

(C) The Author(s) 2012. This article is published with open access at Springerlink.com

\begin{abstract}
The objectively existing in situ stress field and the physical mechanical properties of rock are closely related to the borehole stability in petroleum engineering. However, in present engineering design, rock mass is simply treated as isotropic material. This method may be acceptable for shallow rock engineering, but for deep rock engineering, with the increase of drilling depth, the anisotropic properties of rock mass become stronger and should be considered. In the past, accurate methods to predict critical fracturing or collapse pressures were unavailable. Simple isotropic stress equations have been used to some extent, but these have failed to take into account real rock properties that are clearly anisotropic. On the basis of some rock testing experiments, the vertical borehole stability in transversely isotropic media was the main focus of this study. By solving the stress distribution on the borehole wall, a new vertical borehole stability model was established. The results obtained in this study showed that the anisotropy of the rock and the horizontal stress ratio greatly affect the stress distribution and the failure plane of vertical wellbores. Neglecting this effect can lead to errors in stability predictions. Therefore, it was seen that the effect of the rock anisotropy is of practical importance in the life of a well since it can avoid borehole instability issues.
\end{abstract}

Y. Jin · J. Yuan $(\bowtie) \cdot$ B. Hou $\cdot$ M. Chen $\cdot$ Y. Lu ·

$\mathrm{S}$. Li $\cdot \mathrm{Z}$. Zou

State Key Laboratory of Petroleum Resources and Prospecting,

China University of Petroleum, Beijing,

People's Republic of China

e-mail: jack-331611@163.com
Keywords Borehole stability - Transversely · Isotropic rocks $\cdot$ Tensile failure $\cdot$ Shear failure Horizontal stress ratio · Degree of anisotropic

\begin{tabular}{|c|c|}
\hline \multicolumn{2}{|l|}{ List of symbols } \\
\hline$\sigma_{r}$ & $\begin{array}{l}\text { Radial stress on the wellbore wall } \\
(\mathrm{MPa})\end{array}$ \\
\hline$\sigma_{\theta}$ & $\begin{array}{l}\text { Tangential stress on the wellbore } \\
\text { wall at an angular position } \theta \\
(\mathrm{MPa})\end{array}$ \\
\hline$\sigma_{z}$ & $\begin{array}{l}\text { Axial stress on the wellbore wall } \\
\text { at an angular position } \theta(\mathrm{MPa})\end{array}$ \\
\hline$\tau_{r \theta}, \tau_{r z}, \tau_{\theta z}$ & $\begin{array}{l}\text { Tangential stresses on the wellbore } \\
\text { wall in cylindrical coordinate } \\
\text { system (MPa) }\end{array}$ \\
\hline$\sigma_{x x}, \sigma_{y y}, \sigma_{z z}, \tau_{x y}, \tau_{x z}, \tau_{y z}$ & $\begin{array}{l}\text { Far-field stresses in Cartesian } \\
\text { coordinate system }(\mathrm{MPa})\end{array}$ \\
\hline (a) & $\begin{array}{l}\text { Matrix of coefficients of } \\
\text { deformation }\end{array}$ \\
\hline$P_{w}$ & $\begin{array}{l}\text { Mud weight acting on the } \\
\text { borehole wall }(\mathrm{MPa})\end{array}$ \\
\hline E & $\begin{array}{l}\text { Modulus of elasticity in the plane } \\
\text { of isotropy (MPa) }\end{array}$ \\
\hline$E^{\prime}$ & $\begin{array}{l}\text { Modulus of elasticity in the plane } \\
\text { normal to the plane of isotropy } \\
\text { (MPa) }\end{array}$ \\
\hline$v$ & $\begin{array}{l}\text { Poisson's ratio in the plane of } \\
\text { isotropy }\end{array}$ \\
\hline$v^{\prime}$ & $\begin{array}{l}\text { Poisson's ratio in the plane } \\
\text { normal to the plane of isotropy }\end{array}$ \\
\hline$\sigma_{t}$ & $\begin{array}{l}\text { Tensile strength of the rock } \\
\text { (MPa) }\end{array}$ \\
\hline & Cohesion (MPa) \\
\hline & Angle of internal friction (o) \\
\hline
\end{tabular}

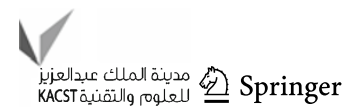




$\begin{array}{ll}\lambda_{i} & \text { The three complex numbers } \\ & (i=1,2,3) \\ & \text { The notation for the real part of } \\ \text { the complex expressions in the } & \text { brackets } \\ & \text { The analytic functions of the } \\ & \text { complex variable } z_{k}=x+\mu_{k} y \\ F_{\left(z_{k}\right)}(k=1,2,3) \quad & \text { The coordinates of the point within } \\ & \text { the body where stress, strain and } \\ & \text { displacement components must } \\ & \text { be determined } \\ & \text { The three analytic functions }\end{array}$

$\phi_{k}(k=1,2,3)$ predict critical fracturing or collapse pressures have so far been unavailable. Results obtained in this way usually lack accuracy, they neglect the effect of anisotropy, and can lead to inaccurate conclusions when designing corresponding mud density during the well drilling process. They can thus result in serious borehole instability accidents. Therefore, the issue of rock anisotropy should not be ignored.

The importance of accounting for rock anisotropy in engineering problems is scale-dependent: it depends on the relative size of the problem being investigated, with respect to the size of the rock features such as strata or bed thickness and joint spacing. This paper sets out to further understand the actual situation of the well site taking anisotropy into account. It investigates the effect of the rock anisotropy in the stability and the stress distribution at the wall of vertical wellbores. The closed-form solution for stress distribution in transversely isotropic materials was used on the basis of rock experiments. A program was developed to compute the stress components at the borehole wall whereby sensitivity analyses were performed to analyze the effect of the elastic moduli and stress anisotropy. Tensile and shear failure criteria were considered for the borehole stability analysis.

\section{The different mechanical properties between the isotropy plane and normal plane}

This paper mainly deals with borehole stability of transversely isotropic formation. This special laminar texture kind of formation bears the following characteristics: In parallel bedding directions (horizontal), its physical and mechanical properties are very close and can be approximately considered as the same; however, great differences exist between any direction of the bedding plane and that of the vertical bedding. From a macroscopic perspective, these properties are obviously anisotropic. Based on the theory above, we therefore cored from the same rock in the vertical bedding direction and parallel bedding direction, respectively (shown in Fig. 1).

After coring in these two directions of rock samples, we conducted Triaxial Compression Tests using Changchun Sunrise TAW-1000 Deep Water Pore Pressure Servo-system, and its stress-strain curves are shown in Fig. 2. The results of this experiment indicated that the compressive strength of the rock core in the plane of isotropy to be 175.345 MPa, modulus of elasticity 27.96 GPa, and Poisson's ratio 0.356. Similarly, results for the plane normal were found to be $106.812 \mathrm{MPa}$, modulus of elasticity 14.33 $\mathrm{GPa}$, and Poisson's ratio 0.352. From these results it can clearly be seen that the respective mechanical properties 
Fig. 1 Schematic diagram of mudstone coring ( $L$ coring in the plane of isotropy, $R$ coring in the plane normal to the plane of isotropy)
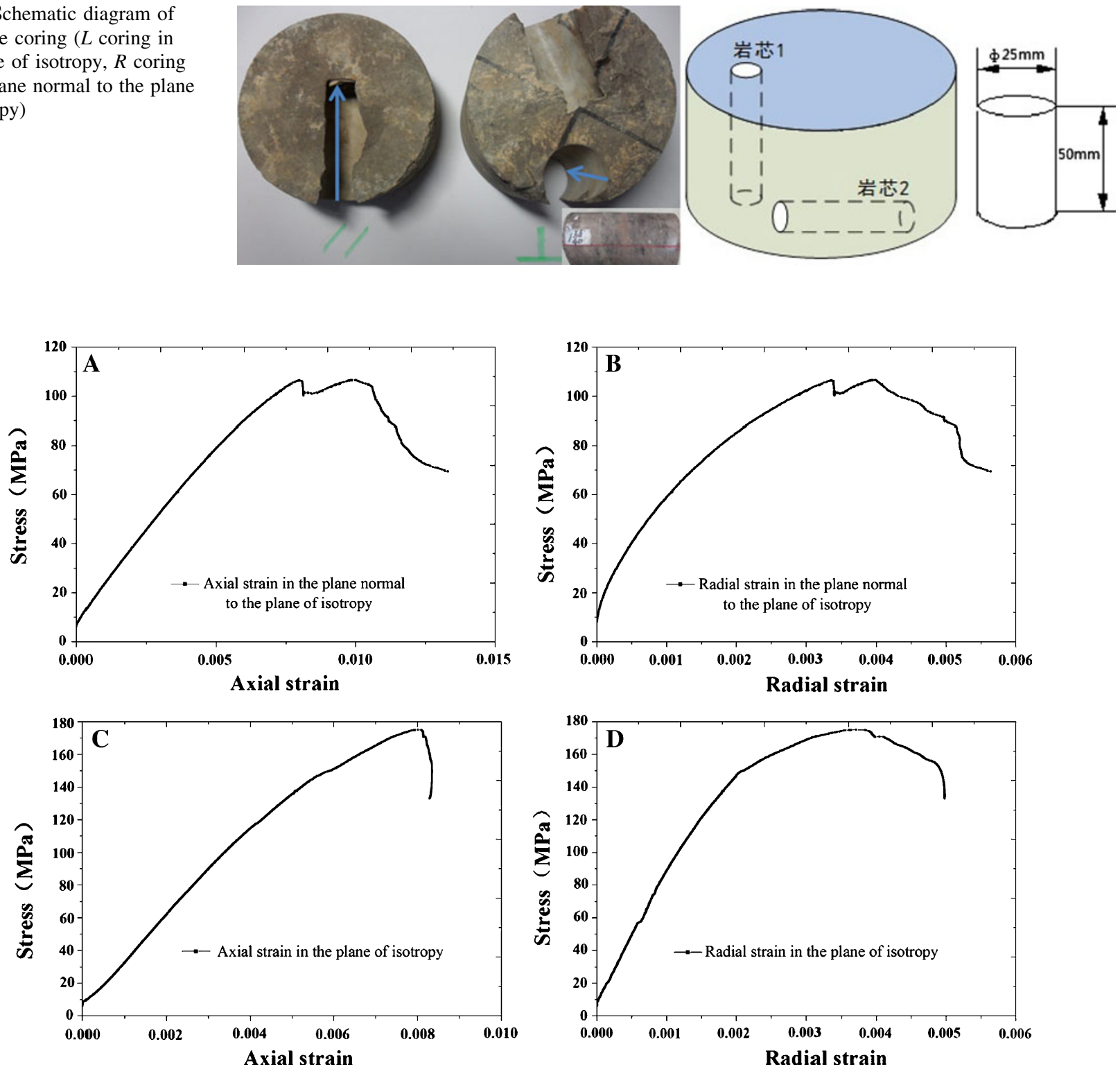

Fig. 2 Stress-strain curve of Triaxial compression test (Confining pressure is $40 \mathrm{MPa}, \mathbf{a}, \mathbf{b}$ is coring in the plane normal to the plane of isotropy; $\mathbf{c}, \mathbf{d}$ is coring in the plane of isotropy)

show a significant difference between bedding plane and normal direction: hence the anisotropy of the rock is obvious.

Worotnicki (1993) tested 200 groups of rock core, and its results showed that the degree of anisotropy existed in great difference between various types of rock. He classified anisotropic rocks into four groups, viz:

1. Quartzofeldespathic rocks (e.g. granites, quartz and arkose sandstones, granulites and gneisses);

2. Basic/lithic rocks (igneous rocks);

3. Pelitic clays and pelitic micas rocks (e.g. mudstones, slates, phyllites and schists); and,
4. Carbonate rocks (e.g. limestones, marbles and dolomites).

According to the methods above and Worotnicki's classification, 40 groups' rock experiments were completed, each giving the degree of three types of the rock anisotropy's range of variation, as shown in Table 1 . The changes of the mudstone's elastic parameters were mainly studied. By analysis, the following conclusions were obtained:

1. The ratio of mudstone's transverse and longitudinal modulus of elasticity is basically below 5, and Poisson's ratio ranges between 0.1 and 0.4 . 
Table 1 Degree of anisotropy of different types of rock

\begin{tabular}{|c|c|c|}
\hline Rock types & $\begin{array}{l}\text { Degree of } \\
\text { anisotropic }\end{array}$ & $E_{\max } / E_{\min }$ \\
\hline Quartzofeldespathic & Low to moderate & $\begin{array}{l}E_{\max } / E_{\min }<3.5(80 \% \\
\quad<1.5)\end{array}$ \\
\hline $\begin{array}{l}\text { Pelitic clays } \\
\text { (mudstone) }\end{array}$ & Moderate to high & $E_{\max } / E_{\min }<6(50 \%<2)$ \\
\hline Carbonates & Intermediate & $E_{\max } / E_{\min }<1.7$ \\
\hline
\end{tabular}

2. Stresses have an influence on rock anisotropy, when the anisotropy is induced by joints; the degree of anisotropy can be much higher and is influenced by the respectively. In the actual process of vertical well drilling in the transverse isotropy formations there are two kinds of borehole conditions. One is the transversal isotropy in a plane perpendicular to the hole axis, where the isotropic plane consists of $x$ and $y$ axes, as shown in Fig. 3. Another situation is the transversal isotropy in a plane striking parallel to the hole axis, also where the isotropic plane consists of $x$ and $z$ axes, and which is shown in Fig. 4. Through calculation and analysis, we found that the values for the stress components when the borehole axis is perpendicular to the isotropic plane were the same as in the isotropic solutions. In this paper the second case was mainly considered. The specific stress-strain equations are shown as Eq. 2.

$$
\left[\begin{array}{c}
\varepsilon_{x} \\
\varepsilon_{y} \\
\varepsilon_{z} \\
\gamma_{y z} \\
\gamma_{x z} \\
\gamma_{x y}
\end{array}\right]=\left[\begin{array}{llllll}
\frac{1}{E} & -\frac{v^{\prime}}{E^{\prime}} & -\frac{v}{E} & 0 & 0 & 0 \\
-\frac{v^{\prime}}{E^{\prime}} & \frac{1}{E^{\prime}} & -\frac{v^{\prime}}{E} & 0 & 0 & 0 \\
-\frac{v}{E} & -\frac{v^{\prime}}{E} & \frac{1}{E} & 0 & 0 & 0 \\
0 & 0 & 0 & \frac{1}{E}+\frac{1}{E^{\prime}}+2 \frac{v^{\prime}}{E^{\prime}} & 0 & 0 \\
0 & 0 & 0 & 0 & \frac{2(1+v)}{E} & 0 \\
0 & 0 & 0 & 0 & 0 & \frac{1}{E}+\frac{1}{E^{\prime}}+2 \frac{v^{\prime}}{E^{\prime}}
\end{array}\right]\left[\begin{array}{c}
\sigma_{x} \\
\sigma_{y} \\
\sigma_{z} \\
\tau_{y z} \\
\tau_{x z} \\
\tau_{x y}
\end{array}\right]
$$

stresses acting across the joint planes. From the experiments, it can be observed that $E^{\prime}$ and $v^{\prime}$ increase linearly with confinement, whereas $E$ and $v$ remain fairly constant, thus indicating that rock anisotropy decreases with an increase in stress.

\section{Analysis of stress distribution around borehole wall}

Stress components at the borehole wall

In the case of linear elastic material, isotropic or not, if under triaxial state of stress and within elastic range, its stress-strain relation always obeys Generalized Hook's Law. According to this law, the matrix form of the stress distribution at any point of the elastomer can be written as:

$[\varepsilon]=[D][\sigma]$

The independent elastic constant of transverse isotropy reduces to 5. Lekhnitskii (1963) concluded the stress-strain constitutive equations of transverse isotropy. The five independent elastic constants are $a_{11}, a_{12}, a_{13}, a_{33}, a_{44}$
We define the degree of anisotropy (k) using the following expression:

$k=\frac{E}{E^{\prime}}$

For any problem of elastostatics, stress, strain, and displacement components must satisfy the following equations at any point around the hole:

1. Equations of equilibrium;

2. Strain displacement relations;

3. Equations of compatibility for strains;

4. Constitutive relations;

5. Boundary conditions.

The ultimate stress distribution equations should include the following two parts: the far-field stress vector $\sigma_{0}$ before drilling and the boundary stress vector $\sigma_{h}$ along the wall while drilling. The formulation for stress distribution around the borehole is based on the concept of generalized plane strain and linear elastic solid. The final stress distribution equations can be given by (Ong 1994; Amadei 1983, 1984, 1996; Aadnoy 1987): 
Fig. 3 Elastic parameters and stress analysis of borehole in transverse isotropic formations (transverse isotropy in a plane perpendicular to the hole axis)
Fig. 4 Elastic parameters and stress analysis of borehole in transverse isotropic formations (transverse isotropy in a plane striking parallel to the hole axis)
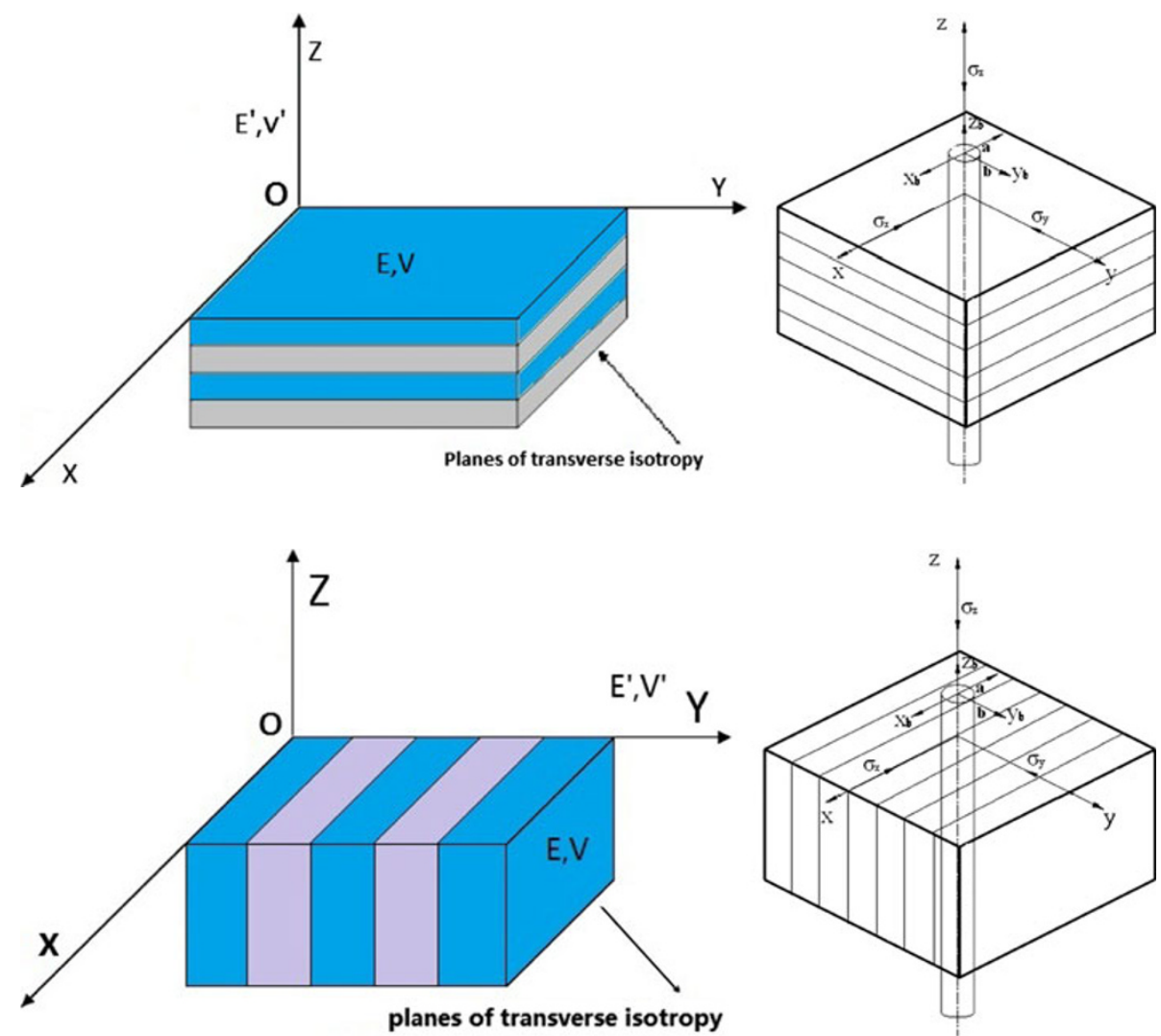

$$
\begin{aligned}
\sigma_{x} & =\sigma_{x, 0}+2 \operatorname{Re}\left[\mu_{1}^{2} \phi_{1}^{\prime}\left(z_{1}\right)+\mu_{2}^{2} \phi_{2}^{\prime}\left(z_{2}\right)+\lambda_{3} \mu_{3}^{2} \phi_{3}^{\prime}\left(z_{3}\right)\right] \\
\sigma_{y}= & \sigma_{y, 0}+2 \operatorname{Re}\left[\phi_{1}^{\prime}\left(z_{1}\right)+\phi_{2}^{\prime}\left(z_{2}\right)+\lambda_{3} \phi_{3}^{\prime}\left(z_{3}\right)\right] \\
\tau_{x y}= & \tau_{x y, 0}-2 \operatorname{Re}\left[\mu_{1} \phi_{1}^{\prime}\left(z_{1}\right)+\mu_{2} \phi_{2}^{\prime}\left(z_{2}\right)+\lambda_{3} \mu_{3} \phi_{3}^{\prime}\left(z_{3}\right)\right] \\
\tau_{x z}= & \tau_{x z, 0}+2 \operatorname{Re}\left[\lambda_{1} \mu_{1} \phi_{1}^{\prime}\left(z_{1}\right)+\lambda_{2} \mu_{2} \phi_{2}^{\prime}\left(z_{2}\right)+\mu_{3} \phi_{3}^{\prime}\left(z_{3}\right)\right] \\
\tau_{y z}= & \tau_{y z, 0}-2 \operatorname{Re}\left[\lambda_{1} \phi_{1}^{\prime}\left(z_{1}\right)+\lambda_{2} \phi_{2}^{\prime}\left(z_{2}\right)+\phi_{3}^{\prime}\left(z_{3}\right)\right] \\
\sigma_{z}= & \sigma_{z, 0}-\frac{1}{a_{33}}\left(a_{31} \sigma_{x, h}+a_{32} \sigma_{y, h}\right. \\
& \left.+a_{34} \tau_{y z, h}+a_{35} \tau_{x z, h}+a_{36} \tau_{x y, h}\right)
\end{aligned}
$$

However, for complicated variable $z_{k}$, analytic function $\phi_{k}\left(z_{k}\right)$ is gained from its boundary conditions. Lekhnitskii (1981) concluded the analytic function expression of any point of the medium. Based on the studies above, the stress distribution around the borehole wall was mainly analyzed in this paper. Consequently, results indicated $x=$ $a \cos \theta, y=a \sin \theta$ around the wall, and through a series of substitution and simplification, we can get analytic function's partial derivative equations along the well wall as follows:

$$
\begin{aligned}
\phi_{1}^{\prime}\left(z_{1}\right)= & \frac{1}{2 \Delta\left(\mu_{1} \cos \theta-\sin \theta\right)} \times\left[D^{\prime}\left(\lambda_{2} \lambda_{3}-1\right)\right. \\
& \left.+E^{\prime}\left(\mu_{2}-\lambda_{2} \lambda_{3} \mu_{3}\right)+F^{\prime} \lambda_{3}\left(\mu_{3}-\mu_{2}\right)\right] \\
\phi_{2}^{\prime}\left(z_{2}\right)= & \frac{1}{2 \Delta\left(\mu_{2} \cos \theta-\sin \theta\right)} \times\left[D^{\prime}\left(1-\lambda_{1} \lambda_{3}\right)\right. \\
& \left.+E^{\prime}\left(\lambda_{1} \lambda_{3} \mu_{3}-\mu_{1}\right)+F^{\prime} \lambda_{3}\left(\mu_{1}-\mu_{3}\right)\right] \\
\phi_{3}^{\prime}\left(z_{3}\right)= & \frac{1}{2 \Delta\left(\mu_{3} \cos \theta-\sin \theta\right)} \times\left[D^{\prime}\left(\lambda_{1}-\lambda_{2}\right)\right. \\
& \left.+E^{\prime}\left(\mu_{1} \lambda_{2}-\mu_{2} \lambda_{1}\right)+F^{\prime}\left(\mu_{2}-\mu_{1}\right)\right]
\end{aligned}
$$

where:

$$
\left.\begin{array}{rl}
\Delta= & \mu_{2}-\mu_{1} \\
D^{\prime}= & \left(P_{w}-\sigma_{x, 0}\right) \cos \theta-\tau_{x y, 0} \sin \theta-i\left(P_{w}-\sigma_{x, 0}\right) \sin \theta \\
& -i \tau_{x y, 0} \cos \theta \\
E^{\prime}= & -\left(P_{w}-\sigma_{y, 0}\right) \sin \theta+\tau_{x y, 0} \cos \theta-i\left(P_{w}-\sigma_{y, 0}\right) \\
& \cos \theta-i \tau_{x y, 0} \sin \theta \\
F^{\prime}= & -\tau_{x z, 0} \cos \theta-\tau_{x z, 0} \sin \theta+i \tau_{x z, 0} \sin \theta-i \tau_{y z, 0} \cos \theta
\end{array}\right\}
$$


The analytical expressions of anisotropic media borehole's stress distribution have been acquired. However, these expressions are extremely complicated and the effects of every specific parameter to the results cannot be identified clearly. Consequently, after determining the five elastic parameters and the far-field stress of the transverse isotropy, this issue was addressed using a computer program, and the results were compared for this isotropic formation. Thus, in this study, a plane of elastic symmetry perpendicular to the borehole axis was considered a special case of anisotropy. It occurs for the following condition: when the rock mass is transversely isotropic with the hole axis perpendicular to the plane of transverse isotropy (shown in Fig. 4). Consequently, these functions can be simplified to the following stress distribution formulas:

$$
\left.\begin{array}{rl}
\sigma_{x} & =\sigma_{x, 0}+2 \operatorname{Re}\left[\mu_{1}^{2} \phi_{1}^{\prime}\left(z_{1}\right)+\mu_{2}^{2} \phi_{2}^{\prime}\left(z_{2}\right)\right] \\
\sigma_{y} & =\sigma_{y, 0}+2 \operatorname{Re}\left[\phi_{1}^{\prime}\left(z_{1}\right)+\phi_{2}^{\prime}\left(z_{2}\right)\right] \\
\tau_{x y} & =\tau_{x y, 0}-2 \operatorname{Re}\left[\mu_{1} \phi_{1}^{\prime}\left(z_{1}\right)+\mu_{2} \phi_{2}^{\prime}\left(z_{2}\right)\right] \\
\tau_{x z} & =\tau_{x z, 0}+2 \operatorname{Re}\left[\mu_{3} \phi_{3}^{\prime}\left(z_{3}\right)\right] \\
\tau_{y z} & =\tau_{y z, 0}-2 \operatorname{Re}\left[\phi_{3}^{\prime}\left(z_{3}\right)\right] \\
\sigma_{z} & =\sigma_{z, 0}-\frac{1}{a_{33}}\left(a_{31} \sigma_{x, h}+a_{32} \sigma_{y, h}\right)
\end{array}\right\}
$$

where:

$$
\left.\begin{array}{l}
\phi_{1}^{\prime}\left(z_{1}\right)=\frac{1}{2 \Delta\left(\mu_{1} \cos \theta-\sin \theta\right)}\left(E^{\prime} \mu_{2}-D^{\prime}\right) \\
\phi_{2}^{\prime}\left(z_{2}\right)=\frac{1}{2 \Delta\left(\mu_{2} \cos \theta-\sin \theta\right)}\left(D^{\prime}-E^{\prime} \mu_{1}\right) \\
\phi_{3}^{\prime}\left(z_{3}\right)=\frac{1}{2 \Delta\left(\mu_{3} \cos \theta-\sin \theta\right)}\left(F^{\prime} \mu_{2}-\mu_{1}\right)
\end{array}\right\}
$$

For vertical borehole, its far-field crustal stresses are:

$$
\left.\begin{array}{rl}
\sigma_{x, 0} & =\sigma_{H} ; \sigma_{y, 0}=\sigma_{h} ; \sigma_{z, 0}=\sigma_{v} \\
\tau_{y z, 0} & =0 ; \tau_{x z, 0}=0 ; \tau_{x y, 0}=0
\end{array}\right\}
$$

The borehole wall stress distribution expressions of transverse isotropic formation are on the basis of arithmetic coordinates $(x, y, z)$. When $\theta=0$, stress vectors are the same as in cylindrical coordinates. However, with the increase of $\theta$, the differences between these two coordinates are become bigger and bigger. As a result, the conversion from the Cartesian coordinate system to the cylindrical coordinate system is demanded. The conversion equation is shown in Eq. 10 .

$\{\sigma\}_{r \theta z}=\left[T_{\sigma}\right]\{\sigma\}_{x y z}$
Using substitute borehole wall stress distribution equations of arithmetic coordinate in the cylindrical coordinates' version can now be obtained, and the formulas are shown as shown in Eq. 11.

$$
\left.\begin{array}{rl}
\sigma_{r} & =\cos ^{2} \theta \sigma_{x}+\sin ^{2} \theta \sigma_{y}+\sin 2 \theta \tau_{x y} \\
\sigma_{\theta} & =\sin ^{2} \theta \sigma_{x}+\cos ^{2} \theta \sigma_{y}-\sin 2 \theta \tau_{x y} \\
\sigma_{z} & =\sigma_{z} \\
\tau_{\theta z} & =\cos \theta \tau_{y z}-\sin \theta \tau_{x z} \\
\tau_{r z} & =\sin \theta \tau_{y z}+\cos \theta \tau_{x z} \\
\tau_{r \theta} & =-0.5 \sin 2 \theta \sigma_{x}+0.5 \sin 2 \theta \sigma_{y}+\left(\cos ^{2} \theta-\sin ^{2} \theta\right) \tau_{x y}
\end{array}\right\}
$$

Model verification

In order to validate the program, the anisotropic solution was evaluated in isotropic conditions and the results were compared with those of the general isotropic solution. Jaeger and Cook (1979) concluded the stress distribution equations of borehole wall when subject to isotropic formations, as shown in Eq. 12:

$$
\left.\begin{array}{l}
\sigma_{r}=p_{w} \\
\sigma_{\theta}=\left(\sigma_{x, o}+\sigma_{y, 0}\right)-2\left(\sigma_{x, 0}-\sigma_{y, 0}\right) \cos 2 \theta-p_{w} \\
\sigma_{z}=\sigma_{z, 0}
\end{array}\right\}
$$

The input data used for the model validation is shown in Table 2.

The distribution of stresses at the wellbore wall was computed from the anisotropic and isotropic solutions given by Eqs. 11 and 12, respectively. The elastic parameters $E$ and $v$ from Table 2 were used for the isotropic case. The anisotropic solution was evaluated at isotropic conditions by taking $E^{\prime} \cong E$ and $v^{\prime} \cong v$ in order to avoid indeterminations generally obtained when such parameters are assumed to be equal. Substitute the validation data (Table 2) of vertical borehole to these two models, respectively. Table 3 shows the results of the tangential stresses obtained with both solutions for a number of borehole angles. It can be observed that when the anisotropic solution is evaluated under isotropic conditions, which the results are almost identical to those obtained with the isotropic solution. These results suggest that the anisotropic model is probably correct and can be used as the base of the model validation. Hence, the stress distribution of any angle can be obtained using the formulas above. With other data such as initial stress, hole direction, mud density and elastic parameters of rock obtained, the degree of anisotropy effect the stress around the wall, can be found, and then the borehole stability can be analyzed. 
Table 2 Input data for isotropic comparison

\begin{tabular}{|c|c|c|c|c|c|c|c|c|c|}
\hline \multicolumn{2}{|c|}{ Wellbore configuration } & \multicolumn{4}{|c|}{ Elastic properties of the formation } & \multicolumn{4}{|c|}{ In Situ stresses } \\
\hline $\begin{array}{c}\text { Wellbore } \\
\text { pressure } \\
(\mathrm{MPa})\end{array}$ & 37.781 (Variable) & $E(\mathrm{MPa})$ & 23,443 & $v$ & 0.15 & $\sigma_{v}(\mathrm{MPa})$ & 63.745 & $\sigma_{h \min }(\mathrm{MPa})$ & 41.076 (Variable) \\
\hline Depth (m) & 3,000 & $E^{\prime}(\mathrm{MPa})$ & 23,443 (Variable) & $v^{\prime}$ & 0.225 (Variable) & $\sigma_{H \max }(\mathrm{MPa})$ & 58.934 & & \\
\hline
\end{tabular}

Table 3 Program validation: tangential stresses

\begin{tabular}{llllll}
\hline \multicolumn{4}{l}{ Tangential stress } & $\sigma_{\theta}(\mathrm{MPa})$ \\
\cline { 2 - 6 }$\theta$ & $\begin{array}{l}\text { Anisotropic } \\
(k=1)\end{array}$ & Isotropic & $\theta$ & $\begin{array}{l}\text { Anisotropic } \\
(k=1)\end{array}$ & Isotropic \\
\hline 0 & 26.5127 & 26.5130 & 200 & 34.8689 & 34.8690 \\
20 & 34.8689 & 34.8690 & 220 & 56.0272 & 56.0270 \\
40 & 56.0272 & 56.0270 & 240 & 80.0871 & 80.0870 \\
60 & 80.0871 & 80.0870 & 260 & 95.7909 & 95.7911 \\
80 & 95.7909 & 95.7911 & 280 & 95.7909 & 95.7911 \\
100 & 95.7909 & 95.7911 & 300 & 80.0871 & 80.0870 \\
120 & 80.0871 & 80.0870 & 320 & 56.0272 & 56.0270 \\
140 & 56.0272 & 56.0270 & 340 & 34.8689 & 34.8690 \\
160 & 34.8689 & 34.8690 & 360 & 26.5127 & 26.5130 \\
180 & 26.5127 & 26.5130 & & & \\
\hline
\end{tabular}

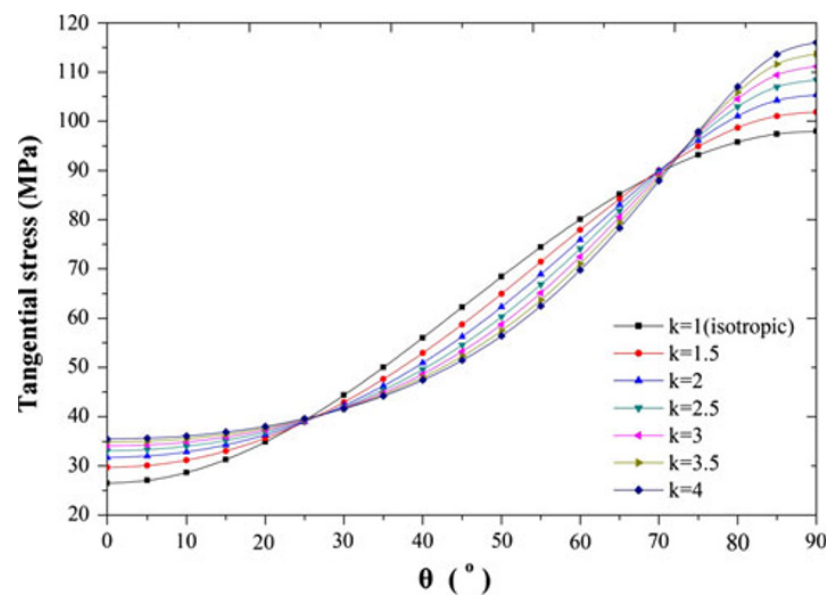

Fig. 5 Tangential stress distribution at the borehole wall for a vertical wellbore in anisotropic formation $(k>1)$

\section{Stress distribution}

Anisotropic formation and crustal stress conditions have a great effect on borehole stability. The degree of this effect can be analyzed by numerical calculation. Assume $\sigma_{V}>\sigma_{H \max }>\sigma_{h \min }($ shown in Table 2), where vertical modulus of elasticity is variable.

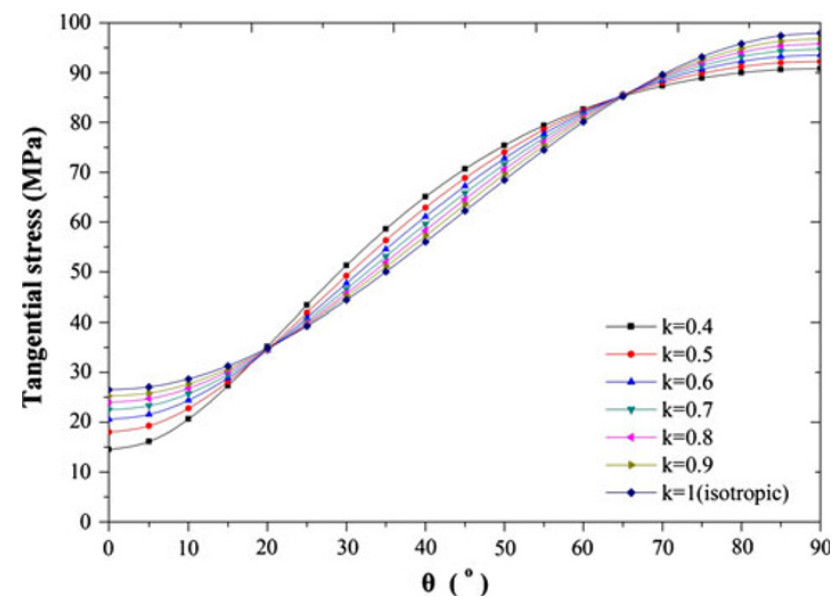

Fig. 6 Tangential stress distribution at the borehole wall for a vertical wellbore in anisotropic formation $(k<1)$

Effect of young's modulus ratio-degree of anisotropy

When the modulus of elasticity in the plane of isotropy is bigger than that in the plane normal to it $(k>1)$, and in the opposite condition $(k<1)$, the tangential stresses of borehole wall are shown in Figs. 5, 6.

When $k>1$, Fig. 5 shows stress distribution of vertical borehole wall under anisotropic and isotropic formations. It indicates that the change trend of tangential stress is not the same at different angular position. When at $\theta=0^{\circ}$, the tangential stress reaches the minimum, whilst the maximum can be found when at $\theta=90^{\circ}$, both in anisotropic and isotropic formations. Furthermore, the tangential stress increases in transverse isotropic formations with the increase of the degree of anisotropy ( $k$ is bigger). In addition, the tangential stress value is always greater than in isotropic formations when $\theta=0^{\circ}$ and $\theta=90^{\circ}$.

Similarly, when $k<1$, Fig. 6 also shows that its tangential stress reaches the minimum at $\theta=0^{\circ}$ and the maximum at $\theta=90^{\circ}$ both in anisotropic and isotropic formations when $\theta=0^{\circ}$. And the tangential stress increases in transverse isotropic formations when the decrease of the degree of anisotropy ( $k$ is bigger); and the tangential stress is always smaller than in isotropic formations when $\theta=0^{\circ}$ and $\theta=90^{\circ}$. So the above analysis shows that the degree of anisotropy of rock has a direct impact on the stress distribution. 


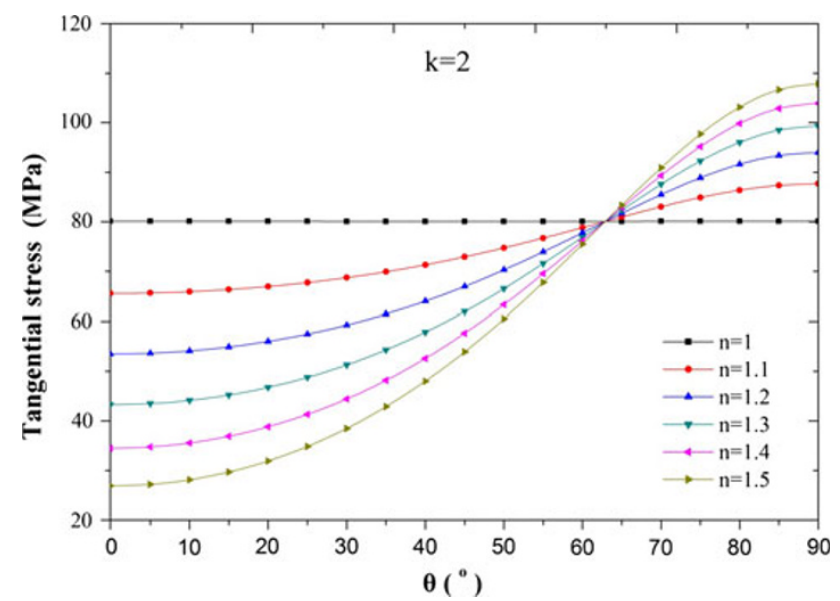

Fig. 7 Tangential stress distribution at different horizontal stress ratio in anisotropic formation $(k=2)$

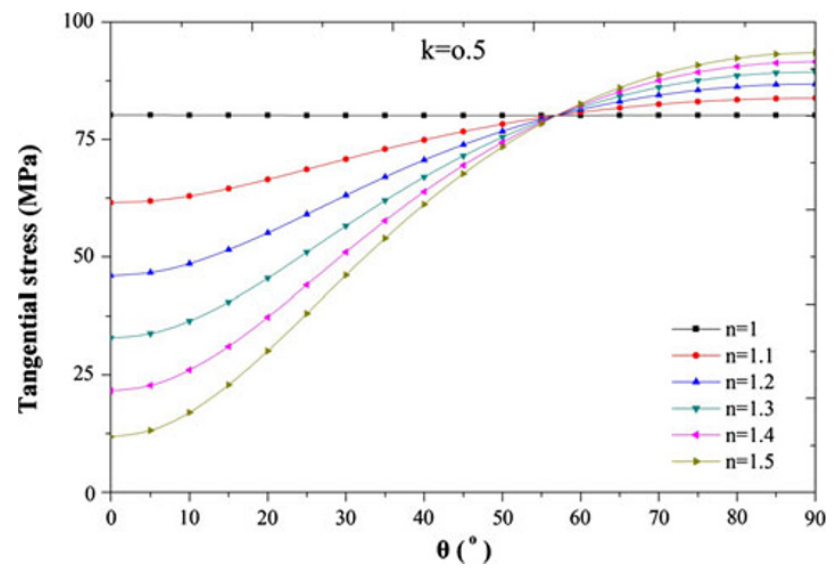

Fig. 8 Tangential stress distribution at different horizontal stress ratio in anisotropic formation $(k=0.5)$

\section{Effect of stress anisotropy}

The ratio of horizontal stress $(n)$ was defined using the following expression:

$n=\sigma_{H} / \sigma_{h}$

When the modulus of elasticity in the plane of isotropy is bigger than that in the plane normal to it $(k=2)$ and the opposite condition $(k=0.5)$, then the tangential stress at borehole wall is as shown in Figs. 7, 8.

From Figs. 7, 8, it can be seen that the tangential stress has the same changed trend, regardless of $k$, with the horizontal stress ratio. When $\theta=0^{\circ}$, the tangential stress in transverse isotropic formations decreases with the increase of the horizontal stress ( $n$ is bigger); when $\theta=90^{\circ}$, the tangential stress increases with the increase of the horizontal stress ( $n$ is bigger).
Table 4 Rock properties for failure criteria analysis

\begin{tabular}{lc}
\hline Tensile strength of the rock $\sigma_{t}(\mathrm{MPa})$ & 3.2 \\
\hline Cohesion $C(\mathrm{MPa})$ & 8.1 \\
Angle of internal friction $\phi(\circ)$ & 20
\end{tabular}

\section{Borehole stability analysis}

The sidewall principal stress can be expressed in different versions according to various sidewall stress states. By calculation, the following stress state of borehole wall can be obtained: when $\sigma_{\theta}>\sigma_{z}>\sigma_{r}$, the maximum and minimum principal stresses are $\sigma_{1}=\sigma_{\theta}, \sigma_{3}=\sigma_{r}$ respectively. For vertical borehole, at any point, two principal stresses $\sigma_{1}=\sigma_{\theta}>\sigma_{3}=\sigma_{r}$ must be taken into consideration. The basic strength parameters of rock are shown in Table 4 .

The failure criteria thus obtained can now be used to determine whether a vertical borehole would fail under the stress state, borehole configuration and rock properties as defined in Table 2. Such criteria were also used to evaluate how far the prediction obtained with the isotropic model was from the prediction obtained with the actual anisotropic properties of the rock.

Tensile failure

From the perspective of mechanics, the reason why the formation breakdown occurred was because of the high mud density in the borehole, making the tangential stress greater than the tension strength of rock, that is:

$\sigma_{\theta} \geq-\sigma_{t}$

When this tensile force becomes strong enough to overcome the tension strength of the rock, then the formation begins to fracture, leading to circulation loss. The fracture occurs at the point where $\sigma_{\theta}$ reaches the minimum,

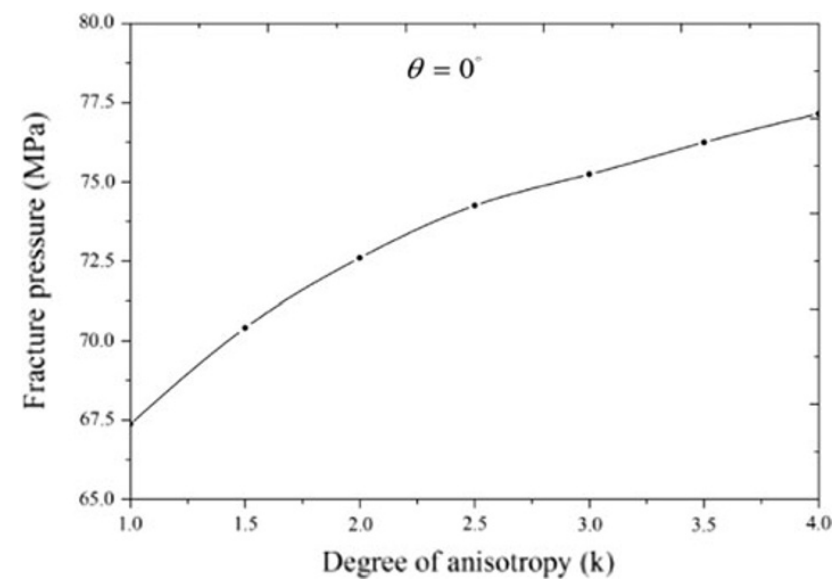

Fig. 9 Effect of degree of anisotropy on fracture pressure for a vertical wellbore in anisotropic formation $\left(k>1, \theta=0^{\circ}\right)$ 


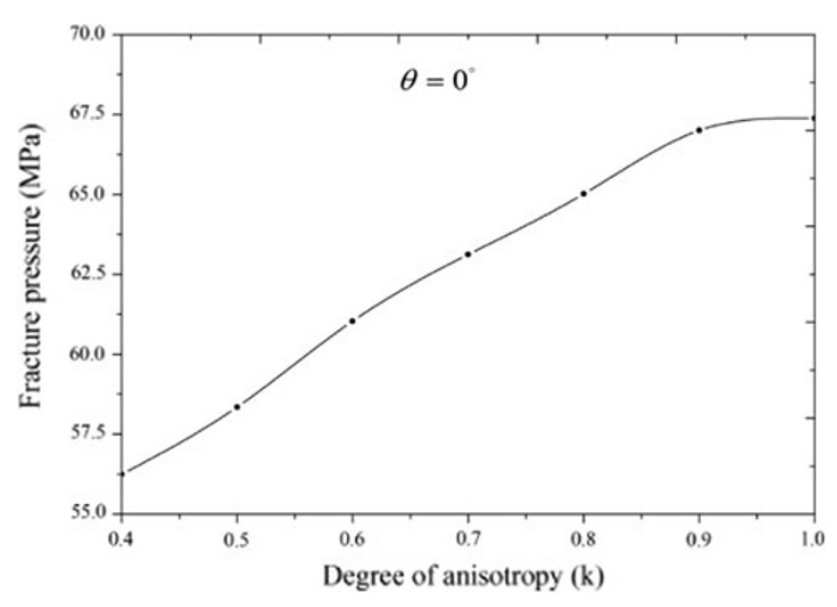

Fig. 10 Effect of degree of anisotropy on fracture pressure for a vertical wellbore in anisotropic formation $\left(k<1, \theta=0^{\circ}\right)$

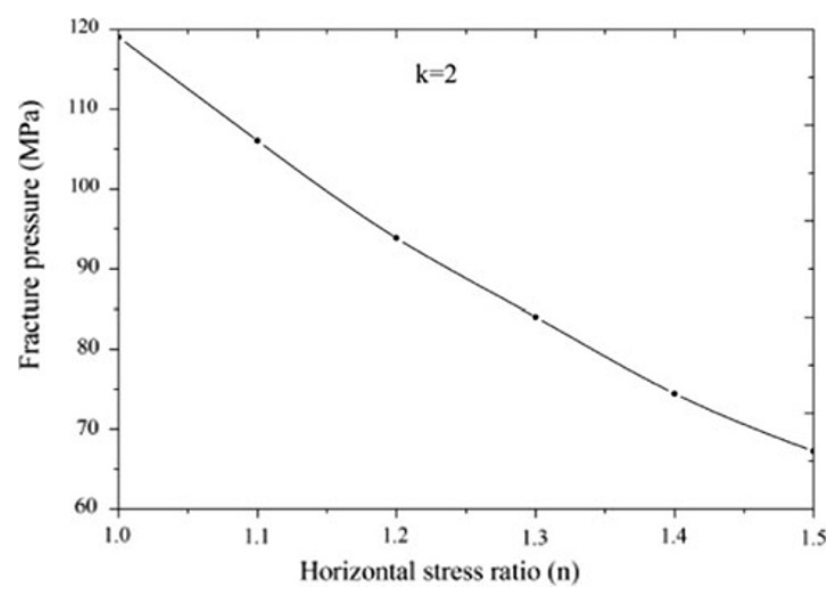

Fig. 11 Effect of horizontal stress ratio on fracture pressure for a vertical wellbore in anisotropic formation $\left(k=2, \theta=0^{\circ}\right)$

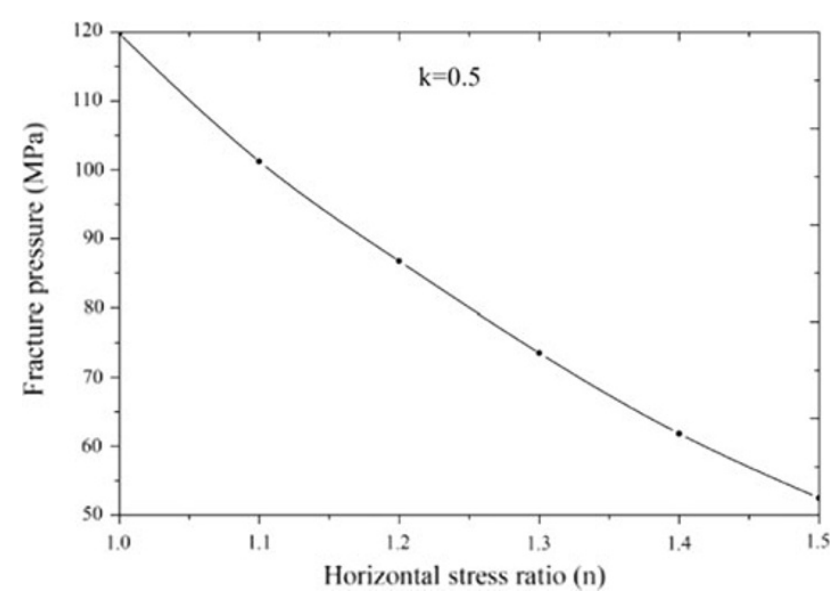

Fig. 12 Effect of horizontal stress ratio on fracture pressure for a vertical wellbore in anisotropic formation $\left(k=0.5, \theta=0^{\circ}\right)$ that is, when $\theta=0^{\circ}$ or $\theta=180^{\circ}$. If one substitutes the maximum principal stress of borehole wall cave into the expressions of tension strength (Eq. 14), then the fluid column pressure of the well, known as fracture pressure, can be obtained. By programming and calculating, we can now obtain the tension failure law of anisotropic formations.

When $k>1$, we know from Fig. 9 that the fracture pressure of anisotropic formation is always greater than isotropic formation, and with the increase in the degree of anisotropy, the fracture pressure increases. Conversely, when $k<1$, Fig. 10 indicates the fracture pressure of anisotropic formation will always be smaller than in isotropic formations, and in anisotropic formations, the fracture pressure will increase gradually with the decrease of the degree of anisotropy ( $k$ is bigger).

From Figs. 11, 12, it can be seen that the fracture pressure in transverse isotropic formations (whether $k>1$ or $k<1)$ decreases with the increase in the horizontal stress ( $n$ is bigger), that is, the greater the ratio of horizontal stress, the easier it will be for tensile failure to happen.

\section{Shear failure}

It can now be seen from the previous stress analysis that when mud density is less than a certain number, shear failure will occur in borehole wall rock, leading to well collapse. For linear elastic material, an approximate collapse pressure is given by Morh-Coulomb Failure Criterion, so a proper analysis of borehole wall failure was made using this criterion for this paper. Besides, since the permeability of argillite is small, the infiltration of drilling mud can be ignored, enabling the well wall to be considered as impermeable. According to this analysis, borehole wall collapse will occur at the point when $\theta=90^{\circ}$ and $\theta=270^{\circ}$, where the effective pressure differential $\sigma_{\theta}-\sigma_{r}$ is the greatest. Applying this data to the Morh-Coulomb Failure Criterion (Eq. 15), if $F \leq 0$, then failure occurs. On the contrary, if one substitutes the maximum and minimum principle stress into Eq. 15 when the collapse occurs, then the critical drilling mud density which maintains the wellbore stability, known as collapse pressure, can be obtained. Similarly, the shear failure trend of different degrees of anisotropy can be analyzed using this method.

$F=\frac{\sigma_{1}+\sigma_{3}}{2} \sin \phi+C \cos \phi-\frac{\sigma_{1}-\sigma_{3}}{2}$

When $k>1$, we can know from Fig. 13 that the collapse pressure of anisotropic formation will always be bigger than when it exists in isotropic formation. Besides, in anisotropic formation, with the increase of the degree of anisotropy, the collapse pressure will increase gradually. However, when the condition is on the contrary $(k<1)$, 


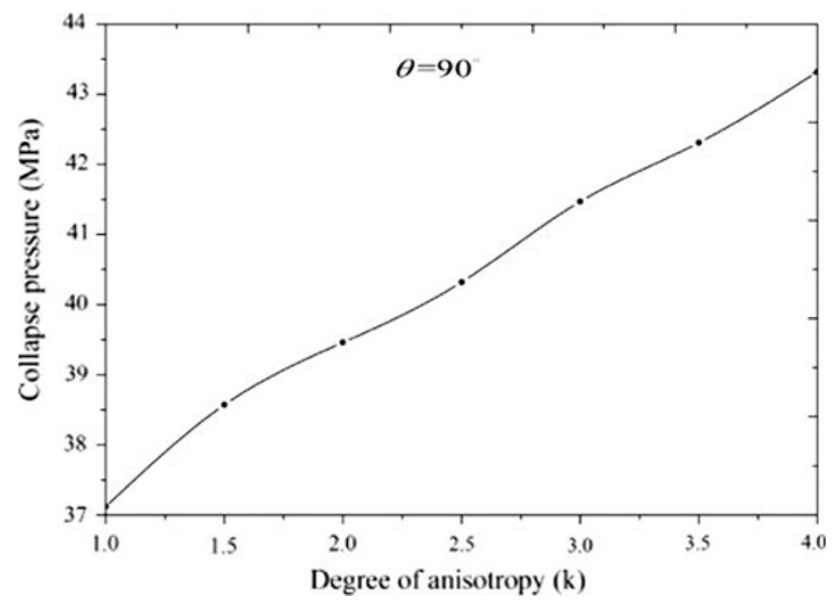

Fig. 13 Effect of degree of anisotropy on collapse pressure for a vertical wellbore in anisotropic formation $\left(k>1, \theta=90^{\circ}\right)$

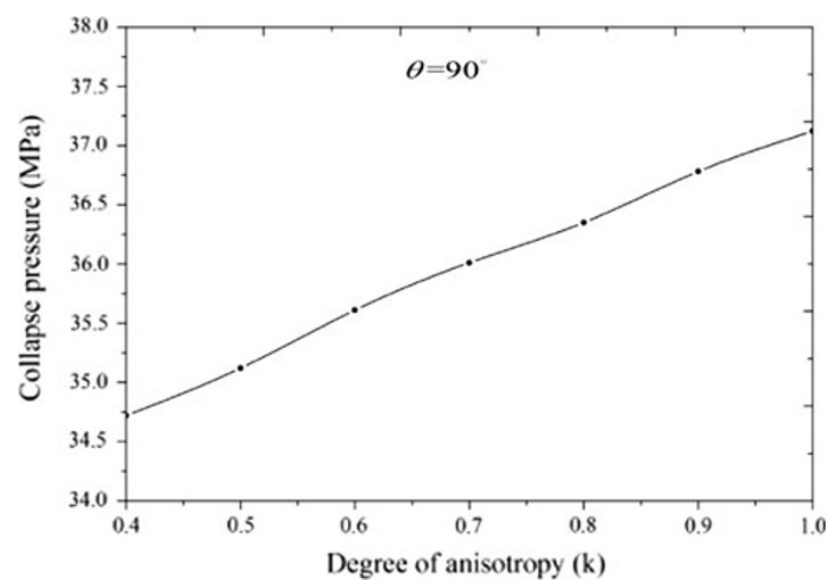

Fig. 14 Effect of degree of anisotropy on collapse pressure for a vertical wellbore in anisotropic formation $\left(k<1, \theta=90^{\circ}\right)$

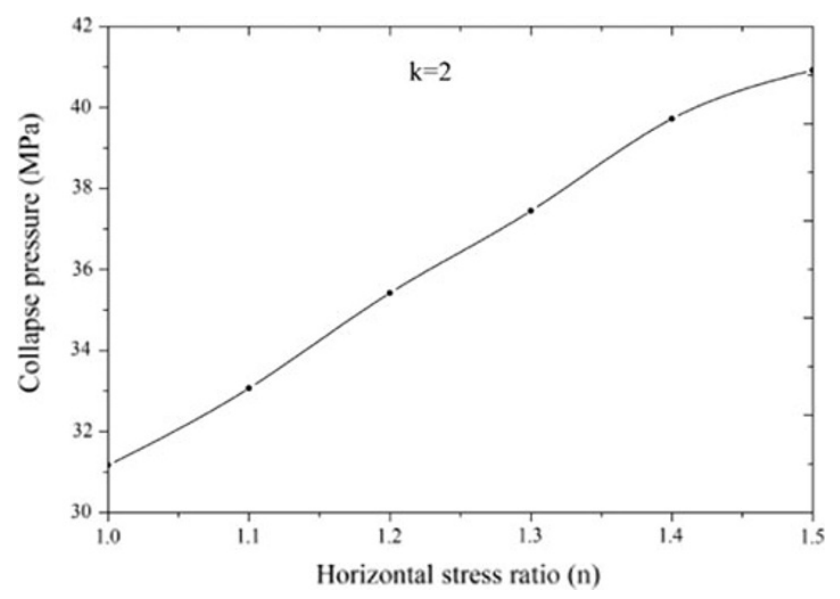

Fig. 15 Effect of horizontal stress ratio on collapse pressure for a vertical wellbore in anisotropic formation $\left(k=2, \theta=90^{\circ}\right)$

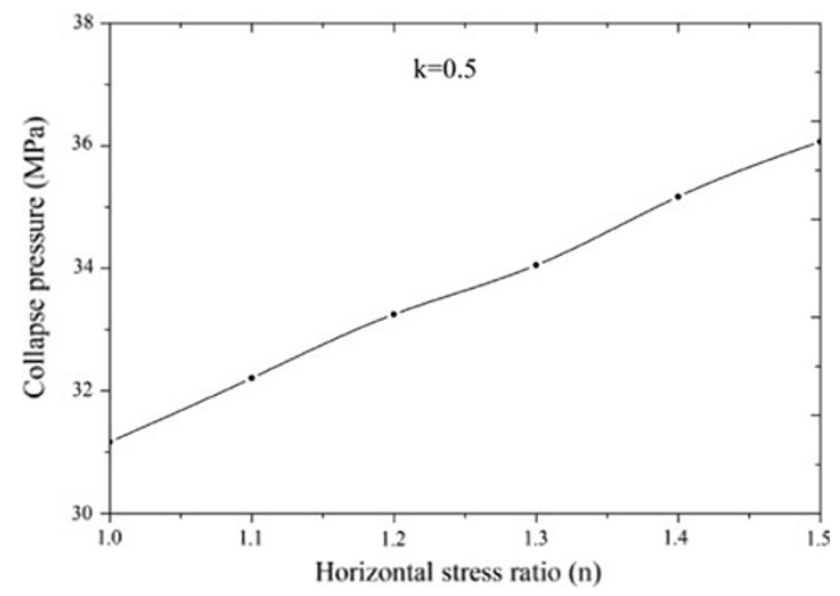

Fig. 16 Effect of horizontal stress ratio on collapse pressure for a vertical wellbore in anisotropic formation $\left(k=0.5, \theta=90^{\circ}\right)$

Fig. 14 indicates that when in anisotropic formation, the collapse pressure increases with the decrease of the degree of anisotropy ( $\mathrm{k}$ is bigger), the value being always less than when in isotropic formation.

From Figs. 15, 16, it can be seen that the collapse pressure in transverse isotropic formations (whether $k>1$ or $k<1$ ) increases gradually with the increase of ratio of the horizontal stress ( $n$ is bigger).

From the above analysis, it can be seen that the degree of rock anisotropy and horizontal stress ratio affects the condition of stress of adjacent rock, thus leading to the difference between collapse pressure and fracture pressure. This further suggests that rock anisotropy cannot be ignored when analyzing borehole stability, and when drilling the formation having a high anisotropy, appropriate, and indeed, necessary attention should be paid to this.

\section{Conclusions}

This paper mainly deals with vertical borehole stability when drilling in transverse isotropic formation. By solving borehole wall stress distribution of transverse isotropic formation, a new borehole stability model has been established. Using this model, it can now be found out how the elastic parameters of anisotropic rock affect the stress distribution of borehole wall, and the corresponding borehole stability. The following conclusions can be summarized based on the analysis used:

- Under the condition of heterogeneous crustal stress, whether the formation is isotropic or not, the stress distribution of adjacent rock is characterized as heterogeneous. However, when the formation is anisotropic, the maximum stress of the borehole wall is greater than 
when in isotropic condition. To summarize, this anisotropic character intensifies the effect of heterogeneous crustal stress, thus having negative effect on the borehole. In certain geologic conditions, this effect may results in accidents. Consequently, this effect must be recognized and taken seriously.

In anisotropic formation, when $\theta$ is different, then the degree of anisotropy and the horizontal stress ratio have different effects on the stress of adjacent rock. All in all, the degree of anisotropy has a great effect on the maximum and intermediate principal stresses. Hence, we need to measure the modulus of elasticity of rock more accurately in the lab, so as to improve the degree of accuracy when predicting borehole stability.

- The degree of anisotropy and the horizontal stress ratio have a great effect on the fracture and collapse pressures of adjacent rock. The trend of the boreholes to fail in tension decreases with the degree of anisotropy, $k$. On the other hand, the trend to fail in shear increases with the $k$. Neglecting the effect of the anisotropy during borehole stability analyses can lead to make erroneous decisions of the mud pressure that should be used when dealing with this type of formations. Consequently, it is important that an appropriate model is used according to the practical situation of different formations.

- The analysis and solutions stated in this paper are based on linear elastic theory, and the porous elastic effect is ignored. Besides, when analyzing the stress of adjacent rock, the permeability of rock and the effect of temperature and chemistry are also ignored. Hence, these effects can be included in later research. Further confirmatory analysis can also be conducted with lab fracture experiments, thus oilfield practice can be better guided by the results so obtained.

Acknowledgments This paper was supported by the Program for New Century Excellent Talents at the China University of Petroleum, the Ministry of Education of China, 973 Program (2010 CBN226700), and by Program of New Century Excellent Talents for Ministry of Education (NCET-08-0840).

Open Access This article is distributed under the terms of the Creative Commons Attribution License which permits any use, distribution, and reproduction in any medium, provided the original author(s) and the source are credited.

\section{References}

Aadnoy BS (1987) Continuum mechanics analysis of the stability of inclined boreholes in anisotropic rock formations. $\mathrm{PhD}$ thesis, Norwegian Institute of Technology. University of Trondheim, Norway

Aadnoy BS (1991) Effects of reservoir depletion on borehole stability. J Petrol Sci Eng 5:57-61

Amadei B (1983) Rock anisotropy and the theory of stress measurements (lecture notes in engineering; 2). Springer, Berlin

Amadei B (1984) In situ stress measurements in anisotropic rock. Int J Rock Mech Min Sci Geomech Abstr 21(6):327-338

Amadei B (1996) Importance of anisotropy when estimating and measuring in situ stresses in rock. Int J Rock Mech Min Sci Geomech Abstr 33(3):293-325

Chen X, Yang Q, He MC, Li KF (2005) Stability analysis of wellbore based on anisotropic strength criterion for deep jointed rock mass. Chin J Rock Mech Eng 24(16):2882-2888 (In Chinese)

Gao DL, Chen M, Wang JX (1997) Discussion on borehole wall stability. Oil Drill Prod Technol 19(1):1-4 (In Chinese)

Jaeger JC, Cook NGW (1979) Fundamentals of rock mechanics, 3rd edn. Chapman and Hall, London

Lekhnitskii SG (1963) General equations of the theory of elasticity of an anisotropic body. P. Fern, Translator. Holden-Da, Inc, San Francisco, CA

Lekhnitskii SG (1981) Theory of elasticity of an anisotropic body. Mir Publishers, Moscow

Li XW (1983) Rock mechanics properties. China Coal Industry Publishing House, Beijing, China, pp 10-15 (In Chinese)

Liu DY, Zhu KS (1998) A study of strength anisotropy of rock mass containing intermittent joints. Chin J Rock Mech Eng 17(4):366-371 (In Chinese)

Ong SH (1994) Borehole stability. PhD dissertation, University of Oklahoma, Norman, Oklahoma

Wang HX (1987) Principles of hydraulic fracturing. Petroleum Industry Press, Beijing, China, pp 1-5 (In Chinese)

Worotnicki G (1993) CSIRO triaxial stress measurement cell. In: Houdson JA (ed) Comprehensive rock engineering, Chap. 13, Vol. 3. Pergamon, Oxford, pp 329-394 